\title{
A Short Review on Anti-diabetics for Uncontrolled Type 2 Diabetes Mellitus
}

\author{
Hussain Ahmad ${ }^{* 1}$, Md. Abu Nayeem Chowdhury ${ }^{2}$
}

\begin{abstract}
Introduction: This article reviews the treatments available for patients with T2DM, with an emphasis on agents introduced within the last decade. Materials and Methods: This review is based on a search of Medline, the Cochrane Database of Systemic Reviews, and citation lists of relevant publications. Subject heading and key words used include type 2 diabetes mellitus, prevalence, current diagnosis, and current treatment. Only articles in English were included. Materials \& Methods: Screening and diagnosis is still based on World Health Organization (WHO) and American Diabetes Association (ADA) criteria which include both clinical and laboratory parameters. No cure has yet been found for the disease; however, treatment modalities include lifestyle modifications, treatment of obesity, oral hypoglycemic agents, and insulin sensitizers is still the recommended first line medication. Other effective medications include non-sulfonylurea secretagogues, thiazolidinediones, alpha glucosidase inhibitors, and insulin. Recent research into the pathophysiology of type 2 DM has led to the introduction of new medications like glucagon-like peptide 1 analogoues: dipeptidyl peptidase-IV inhibitors, inhibitors of the sodium-glucose cotransporter 2 and $11 \beta$-hydroxysteroid dehydrogenase 1, insulin-releasing glucokinase activators and pancreatic-G-protein-coupled fatty-acid-receptor agonists, glucagon-receptor antagonists, metabolic inhibitors of hepatic glucose output and quick-release bromocriptine. Discussion: : Screening and diagnosis is still based on World Health Organization (WHO) and American Diabetes Association (ADA) criteria which include both clinical and laboratory parameters. No cure has yet been found for the disease; however, treatment modalities include lifestyle modifications, treatment of obesity, oral hypoglycemic agents, and insulin sensitizers is still the recommended first line medication. Other effective medications include non-sulfonylurea secretagogues, thiazolidinediones, alpha glucosidase inhibitors, and insulin. Recent research into the pathophysiology of type 2 DM has led to the introduction of new medications like glucagon-like peptide 1 analogoues: dipeptidyl peptidase-IV inhibitors, inhibitors of the sodium-glucose cotransporter 2 and 11ß-hydroxysteroid dehydrogenase 1, insulin-releasing glucokinase activators and pancreatic-G-protein-coupled fatty-acid-receptor agonists, glucagon-receptor antagonists, metabolic inhibitors of hepatic glucose output and quick-release bromocriptine. Conclusion: Metformin remains the first choice of treatment for most patients. Other alternative or second-line treatment options should be individualized depending on the characteristics of each patient.

Keywords: Type 2 diabetes mellitus, Diagnosis, Management, Newer drugs.

Number of Figures: 03; Number of References: 35; Number of Correspondences: 02
\end{abstract}

*1. Corresponding Author:

Dr. Hussain Ahmad

Assistant Professor

Department of Pharmacology \& Therapeutics

Sylhet Women's Medical College

Email: dr.hussainjmc@gmail.com

H/P: 01716725485

2. Prof. Dr. Md. Abu Nayeem Chowdhury

Professor

Department of Pharmacology \& Therapeutics

Sylhet Women's Medical College

\section{Introduction}

Diabetes is a group of metabolic diseases characterized by hyperglycemia resulting from defects in insulin secretion, insulin action, or both. The chronic hyperglycemia of diabetes is associated with long-term damage, dysfunction, and failure of different organs, especially the eyes, kidneys, nerves, heart, and blood vessels ${ }^{1}$. For decades, the diagnosis of diabetes was based on plasma glucose criteria, either the fasting plasma glucose (FPG) or the 2-hr value in the 75-gm oral glucose tolerance test $(\text { OGTT })^{2}$. Recently, an International Expert Committee recommended that HbA1c (threshold $\leq 6.5 \%$ ) as a third option to diagnose diabetes mellitus (International Expert Committee, 2009) and ADA include this criteria in $2010^{3}$.

\section{Epidemiology of Diabetes Mellitus:}

Diabetes mellitus (DM) has growing worldwide at an alarming rate. The highest increase is projected to be found in the urban population in developing countries. The International Diabetes Federation (IDF) most recently estimates that, $8.3 \%$ of adults - 382 million people around the world have diabetes in 2013, and the number of people with diabetes is set to rise beyond 592 million less than 25 years. Yet, 175 million (46\%) of cases currently undiagnosed, a vast amount of people with diabetes are progressing towards complications. Around 32 million people die in each year are attributable to complication of diabetes. A further 316 million people with impaired glucose tolerance are at high risk from the disease-an alarming number that is set to reach 471 million by $2035^{4}$.

It is clear that diabetes is an ever growing endemic with no end. Centers for Disease Control and Prevention (CDC) reported that nearly 26 million Americans have diabetes. Diabetes affects $8.3 \%$ of Americans of 
all ages, $11.3 \%$ of adults aged 20 years and older, and $25 \%$ of persons age 65 and older. In 2010 about 215,000 people younger than 20 years had diabetes (type 1 or type 2 ) in the United States 5 . WHO termed diabetes as an emerging epidemic, is the 7 th leading cause of death in the USA. WHO reported that approximately 560 million people worldwide will have diabetes by 2030 . According to this report, Bangladesh has 8.4 million $(10 \%$ of adult population) with diabetes in 2013 and the number is expected to increase to a staggering 11.1 million by $2030^{6}$.

Bangladesh is among the top 10 countries in number suffering by type- 2 diabetes. The other countries suffering by diabetes are India, China, USA, Indonesia, Japan, Russia, Brazil, Italy and Pakistan. The prevalence of IGT in Bangladesh is $8.5 \%$ of adult population, which will rise to $8.8 \%$ by $2025^{7}$. Increasing age and higher BMI were significant risk factors following both IGT and OGTT.

Types of Diabetes mellitus: Diabetes mellitus is classified on the basis of etiology and clinical presentation into four types: type-1diabetes, type- 2 diabetes, gestational diabetes, and other specific types.Type- 1 diabetes results from $\beta$-cell destruction, usually leading to absolute insulin deficiency.Type-2 diabetes results from a progressive insulin secretary defect on the background of insulin resistance.Gestational diabetes mellitus (GDM) is diabetes diagnosed during pregnancy that is not clearly overt diabetes. Other specific types of diabetes due to other cause, e.g., genetic defects in $\beta$-cell function, genetic defects in insulin action, disease of the exocrine pancreas (such as cystic fibrosis), and drug or chemical-induced such as in the treatment of HIV/AIDS or after organ transplantation) ${ }^{8}$.

Aetiology: The cause of type 2 diabetes mellitus appears to involve complex interactions between environmental and genetic factors. The disease may develop when a diabetogenic lifestyle (i.e., excessive caloric intake, inadequate caloric expenditure, obesity) is superimposed on a susceptible genotype. The body mass index (BMI) increases the risk for diabetes varies with different racial groups. For example, persons of Asian ancestry are at increased risk for diabetes at lower levels of overweight as compared with persons of European ancestry ? Hypertension and pre-hypertension are associated with increased risk of developing diabetes in whites than in African Americans ${ }^{10}$. In addition, low birth weight may predispose some individuals to develop type 2 diabetes mellitus ${ }^{11}$.

About $90 \%$ of patients of type- 2 diabetes mellitus are obese. However, a large, population-based prospective study has shown that an energy-dense diet may be a risk factor for the development of diabetes independent of baseline obesity ${ }^{12}$.

Major risk factors: The major risk factors for type 2 diabetes mellitus are the following: (i) Age greater than 45 years; (ii) Weight greater than $120 \%$ of desirable body weight; (iii) Family history of type 2 diabetes in a first-degree relative (e.g., parent or sibling); (iv) Previous impaired glucose tolerance (IGT) or impaired fasting glucose (IFG); (v) Hypertension (BP>140/90 mm Hg) or dyslipidemia (HDL cholesterol level $<40 \mathrm{mg} / \mathrm{dL}$ or triglyceride level $>150 \mathrm{mg} / \mathrm{dL}$ ); (vi) History of gestational diabetes mellitus or of delivering a baby with a birth weight of over $9 \mathrm{lb}$; (vii) Polycystic ovarian syndrome (which results in insulin resistance); (viii) Genetic influences; and (ix) Depression ${ }^{13}$.

Pathophysiology: Diabetic Mellitus is a metabolic disorder characterized by inability to regulate blood glucose. Several pathogenic processes are involved in the development of diabetes. These range from autoimmune destruction of the $\beta$-cells of the pancreas with consequent insulin deficiency to abnormalities that result in resistance to insulin action. The basis of the abnormalities in carbohydrate, fat, and protein metabolism in diabetes is deficient action of insulin on target tissues. Deficient insulin action results from inadequate insulin secretion or diminished tissue responses to insulin at one or more points in the complex pathways of hormone action. Impairment of insulin secretion and defects in insulin action frequently coexist in the same patient, and it is often unclear which abnormality, if either alone, is the primary cause of the hyperglycemia ${ }^{2}$. A simplified scheme for the pathophysiology of abnormal glucose metabolism in type 2 diabetes mellitus is depicted in the figure no. ${ }^{1}$.

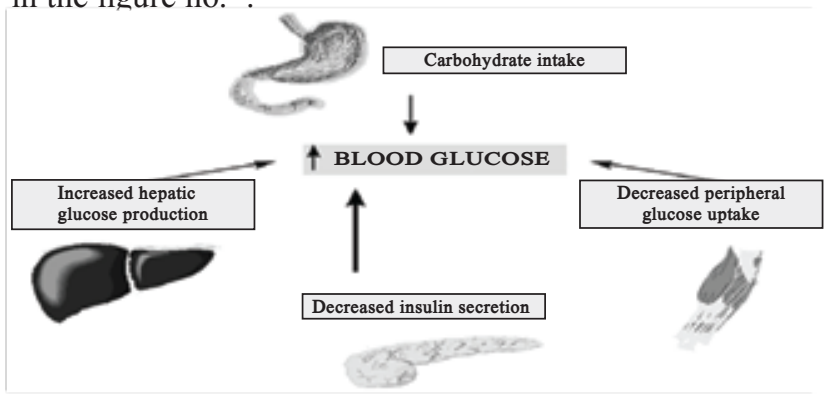

Figure-1: Simplified scheme for the pathophysiology of type 2 diabetes mellitus ${ }^{13}$

Presentation of DM: Symptoms of marked hyperglycemia including polyuria, polyphagia, polydipsia, weight loss, blurred vision and generalized weakness are typical features of diabetes mellitus. Impairment of growth and susceptibility to certain infections may also accompany chronic hyperglycemia. A short list includes non-healing wound infection, infertility or repeated pregnancy loss, undue fatigability, purities vulvae $\mathrm{etc}^{7}$. Acute, life-threatening consequences of uncontrolled diabetes are hyperglycemia with ketoacidosis or the non-ketotic hyperosmolar syndrome ${ }^{2}$.

Diagnosis: The American Diabetes Association current criteria for the diagnosis of diabetes ${ }^{8}$ :

- An HbA1c level of $6.5 \%$ or higher; the test should be performed in a laboratory using immunoassay (by Boronate affinity assay) method that is certified by the National Glycohemoglobin Standardization Program (NGSP) and 
Diabetes Control and Complications Trial (DCCT), or

- A fasting blood glucose (FBG) level of $126 \mathrm{mg} / \mathrm{dL}$ (7.0 $\mathrm{mmol} / \mathrm{L}$ ) or higher; fasting is defined as no caloric diet intake for at least 8 hours before giving blood,and estimated by 'Glucose Oxidase' method, or

- A two-hour post prandial blood glucose level of 200 $\mathrm{mg} / \mathrm{dL}(11.1 \mathrm{mmol} / \mathrm{L})$ or higher during an oral glucose tolerance test (OGTT).

The test should be performed as described by the World Health Organization, using a glucose load containing the equivalent of $75 \mathrm{gm}$ glucose dissolved in $250 \mathrm{ml}$ of water drinking 5-10 min, or

- A random blood glucose of $200 \mathrm{mg} / \mathrm{dL}$ (11.1 mmol/1) or higher in a patient with classical symptoms of hyperglycemia (i.e., polyuria, polydipsia, polyphagia, weight loss) or hyperglycemic crisis.

The American Association of Clinical Endocrinologists, (2010) however recommends that HbA1c be considered an additional optional diagnostic criterion rather than a primary criterion for diagnosis of diabetes ${ }^{14}$.

If hyperglycemia is absent, then $\mathrm{HbA1c}, \mathrm{FBG}$, and OGTT results should be confirmed by repeat testing. The ADA recommends repeating the same test for confirmation, since there will be a greater likelihood of concurrence. However, the diagnosis of diabetes is also confirmed if the results of 2 different tests are above the diagnostic thresholds ${ }^{2}$.

If a patient has 2 different tests and the results are discordant, the test that has a result above the diagnostic threshold should be repeated. A second abnormal result on this test will confirm the diagnosis ${ }^{15}$.

In asymptomatic patients whose random blood glucose level suggests diabetes ( $>140 \mathrm{mg} / \mathrm{dL})$, an FBG or HbA1c level should be measured. FBG level of $100-125 \mathrm{mg} / \mathrm{dL}$ is considered an impaired fasting glucose (IFG), and FBG level of less than $100 \mathrm{mg} / \mathrm{dL}$ is considered as a normal fasting glucose.

Complications of diabetes: Patients with long-standing diabetes are risk of developing a variety of complications. $25 \%$ of people with type- 2 diabetes have evidence of diabetic complications at the time of initial diagnosis. Acute complications of DM are diabetic ketoacidosis, hypoglycaemia, hyperosmolar non ketotic coma and lactic acidosis ${ }^{16}$.

\section{Chronic complications of DM are:}

1. Micro-vascular: (a) Retinopath

(c) Peripheral neuropathy.

2. Macro-vascular: (a) Cerebrovascular disease (b) cardiovascular disease (c) peripheral vascular disease.

3. Others: Gastrointestinal; (a) gastroparesis, diarrhoea (b) genito urinary- uropathy, sexual dysfunction. (c) Dermopathy (d) Infections (e) Cataract glucoma (f) Periodontal disease ${ }^{17}$.

Among the various complications, diabetic neuropathy is relatively early and common complication affecting approximately $30 \%$ of diabetic patients ${ }^{18}$.
Management of Diabetes mellitus:The goals of management of patients with diabetes mellitus are to eliminate symptoms and to prevent the development of complications. Reduction of microvascular complication (i.e., eye and kidney disease) is accomplished through control of hyperglycemia and blood pressure; and that of macrovascular complication (i.e., cardiovascular, cerebrovascular \& peripheral vascular disease), through control of dyslipidemia and hypertension, smoking cessation, aspirin therapy, metabolic and neurologic risk reduction and control of hyperglycemia ${ }^{13}$. An ideal plan of management includes (i) appropriate goal setting, (ii) dietary and exercise modifications, (iii) medications. (iv) appropriate self-monitoring of blood glucose (SMBG) level, (v) regular monitoring for complications, and (vi) Laboratory assessment ${ }^{13}$.

Ideally, blood glucose should be maintained at near-normal levels (preprandial levels of glucose (72-126) $\mathrm{mg} / \mathrm{dL}$ and hemoglobin A1c [HbA1c] levels <7\%). However, focus on glucose alone does not provide adequate treatment for patients with diabetes mellitus. Treatment involves multiple goals (i.e, glycemic status, lipid profile and blood pressure $)^{13}$.There is no cure of diabetes, rather the traditional treatment as diet control, regular exercise \& drug therapy - would control glucose metabolism.

A lot of drugs are using to control diabetes. It becomes difficult to control type 2 diabetes nowadays although we have many drugs. This article reviews the treatments available for patients with T2DM, with an emphasis on agents introduced within the last decade.

\section{Materials and Methods}

This review is based on a search of Medline, the Cochrane Database of Systemic Reviews, and citation lists of relevant publications. Subject heading and key words used include type 2 diabetes mellitus, prevalence, current diagnosis, and current treatment. Only articles in English were included.

Pharmacological Therapy: Early initiation of pharmacological therapy is associated with improved glycemic control and reduced long-term complications in type 2 diabetes. Drug classes used for the treatment of type 2 diabetes include the following:

1) Oral anti-diabetic agent

2) Injectableanti-diabetic agent - Insulin

Oral anti-diabetic agent may be classified as:

a) Insulin Secretagagues:

i. Sulfonylurea-

- 1st generation -Tolbutamide, Chlorpropamide.

- 2nd generation - Glibenclamide, Glipizide, Gliclazide, Glimepiride.

ii. Nonsulphonylureas-

- Meglitinide analogue - Repaglinide.

- D-phenyl-alanine derivatives - Nateglinide

b) Insulin sensitizers

i. Biguanide - Metformin

ii. Thiazolidinediones - Pioglitazone, Rosiglitazone 
c) Alpha-glucosidase inhibitors- Acarbose

d) Incretin based therapy:

i. Dipeptidyl peptidase IV inhibitors - Sitagliptin, Vildagliptin, Saxagliptin and Linagliptin

ii. Glucagon like peptide-1(GLP-1) analogues - exenatide, (Subcutenious rout), Liraglutide ${ }^{7,19}$.

e) Na-glucose co-transporter-2 inhibitor in renal tubles Dapagliflozine.

\section{Injectable agents (Insulin) may be classified as:}

a) Conventional: Short acting (regular insulin), intermediate acting (NPH, lente), and long acting (ultralente)

b) Analogues: rapid acting analogues (aspart, lispro, glulisine), long acting analogues (glargine, detemir, degludac)

c) Pre-mixed insulin (conventional and analogues) ${ }^{20}$.

\section{Mechanism of action of different Oral anti-diabetic drugs:}

Mechanism of different oral anti-diabetic agent describes briefly in the Figure no. 2. Insulin secretogogues - like sulfonylureas, meglitinides, and phenylalanine derivatives - stimulate more Insulin secretion; and Biguanides acts against Insulin resistance and enhance Insulin activity. They both thus prevent blood glucose level to be raised in type 2 diabetic patient. Thiazolidinediones enhance peripheral glucose uptake, mostly by the skeletal muscles. And alpha-glucosidase inhibitors prevent well absorption of carbohydrate from the intestine.

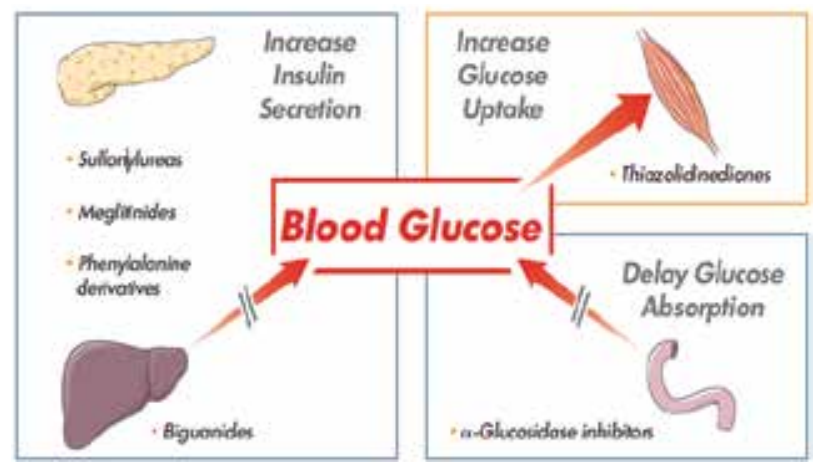

Figure-2: Mechanism of action of different OADs ${ }^{21}$

Doses and duration of Gliclazide for treatment of diabetes mellitus:

Daily total dose of Gliclazide is 40-320 mg, dosing schedule is 1 to 2 times/day and duration of action is $12-24$ hours ${ }^{20}$.

Indication: Type 2 diabetes mellitus patient ${ }^{20}$.

Advantage: Potent; reduce pre- and post-prandial BG (Blood glucose) ${ }^{7}$.

Disadvantage: Hypoglycemia,Gastro-intestinalup set, Weight gain ${ }^{20}$.

Limitation: Impaired hepatic and renal function ${ }^{20}$.

Pharmacokinetics of metformin: Only route of administration is oral; well absorbed from G.I.T.Maximum duration of action: 24 hours; $t^{1 / 2}$ is 1.5 -3hours hour. It is not bound to plasma protein; not metabolized in liver; and excreted unchanged by the kidneys ${ }^{20}$.

Mechanism of action of metformin: Metformin acts by reduction of hepatic glucose production, enhancement of insulin sensitivity and increasing glucose uptake by peripheral tissues ${ }^{20}$.

Doses and duration of Metformin for treatment of diabetes mellitus:Total daily dose of metformin is $500-2550 \mathrm{mg}$, dosing schedule is 2-3 times/day and duration of action is 8-12 hours ${ }^{20}$.

Indication of Metformin: Patient with Type 2 diabetes mellitus, gestational diabetes mellitus, pregnant patient with existing type $2 \mathrm{DM}$, Polycystic ovarian syndrome ${ }^{20}$.

Advantage: Improves insulin sensitivity, weight reduction, reduce pre- (mostly) and post-prandial blood glucose, favorable effects on lipid profile ${ }^{7}$.

Disadvantage: G.I.T. upsetsinclude Anorexia, Nausea, Vomiting, Diarrhoea, lactic acidosis ${ }^{20}$.

Limitation: Impaired renal and hepatic function ${ }^{20}$.

Insulin in type 2 DM: Due to progressive nature of type 2 $\mathrm{DM}$, many individuals require insulin to optimize glycemic control over time as oral hypoglycemic agents fail to achieve targets. This failure termed as primary and secondary $\mathrm{OHA}$ failure ${ }^{7}$. The incidence of secondary drug failure, as published in literature is $0.3 \%$ to $30 \%{ }^{22}$. So, alternative treatment option is needed for controlling blood glucose level. Recently introduced incretin based therapies has been opened new hope for glycemic control in DM treatment ${ }^{23}$.

Incretin and incretin based therapies for Diabetes treatment: Incretins are local hormones that are released after ingestion of a meal and augment the secretion of insulin. These hormones are Gastric inhibitory polypeptide (GIP) and Glucagon-like peptide-1 (GLP-1) ${ }^{24}$. Current research suggests that GLP-1 (glucagon-like peptide-1) is the most important. Because GLP-1 stimulates insulin secretion only under hyperglycemic conditions, there is minimal risk of hypoglycemia; GLP-1 is also associated with increased satiety, possibly because it reduces the rate of gastric emptying. People with type 2 diabetes have reduced circulating levels of GLP-1 but retain their ability to respond to this hormone. Thus, it is possible to improve glycemic control through administration of exogenous GLP-1 ${ }^{25}$. Unfortunately, under normal physiological conditions, GLP-1 and GIP are rapidly degraded by the enzyme system DPP-IV and therefore are not themselves viable as pharmacological agents ${ }^{23}$. Agents that act as incretin mimetic, such as exenatide and liraglutide, and DPP-4 inhibitors, such as sitagliptin, vildagliptin, linagliptin and saxagliptin, improve glycated hemoglobin levels either as monotherapy or in combination with other agents. Importantly, these agents either lead to weight loss or are weight neutral and are associated with a low risk of hypoglycemia - properties that further contribute to their clinical utility. Although DPP-IV inhibition has been 
associated with an enhancement of beta-cell survival and neogenesis in streptozotocin-treated diabetic rats, this effect has not yet been demonstrated in humans. This exciting possibility undoubtedly will be evaluated in humans as a potential agent or class of agents for the prevention of type 2 diabetes ${ }^{25}$.

Pharmacology of Sitagliptin: Sitagliptin is a new oral hypoglycemic (anti-diabetic drug) of the new dipeptidyl peptidase-4 (DPP-4) inhibitor class of drugs. This enzyme-inhibiting drug is to be used either alone or in combination with metformin or a thiazolidinedione for control of type 2 diabetes mellitus ${ }^{7}$. Sitagliptin (previously identided as MK-0431) was the first commercialized orally active, potent and selective inhibitor of DPP-4. It is currently available as single agent or in fixed-dose combination with metformin. According to in vitro studies, sitagliptin is not an inhibitor of CYP isozymes CYP3A4, $2 \mathrm{C} 8,2 \mathrm{C} 9,2 \mathrm{D} 6,1 \mathrm{~A} 2,2 \mathrm{C} 19$ or $2 \mathrm{~B} 6$, and is not an inducer of CYP3A4. Based on these results, sitagliptin is considered unlikely to cause interactions with other drugs that utilize these pathways. Sitagliptin is not extensively bound to plasma proteins. Therefore, the propensity of sitagliptin to be involved in clinically meaningful drug-drug interactions mediated by plasma protein binding displacement is very low ${ }^{26}$.

Pharmacokinetics of Sitagliptin: Sitagliptin is absorbed effectively from the small intestine. It circulates in primarily in unbound form; not appear to undergo extensive metabolism and nor do they affect the hepatic cytochrome oxidase system. The primary route of excretion of radioactivity was via the kidneys, with a mean value of $87 \%$ of the administered dose recovered in urine. Mean faecal excretion was $13 \%$ of the administered dose. Parent drug was the major radioactive component in plasma, urine and faeces, with only $16 \%$ of the dose excreted as metabolites (13\% in urine and $3 \%$ in faeces), indicating that sitagliptin was eliminated primarily by renal excretion and lower doses should be used in patients with reduced renal function ${ }^{26}$.

Pharmacodynamics of Sitagliptin: Gut hormones or incretins (e.g. glucagon like peptide1/GLP1 and glucose dependent insulinotropic polypeptide/GIP) lower blood glucose by:

1. Increasing insulin secretion by glucose-dependent manner.

2. Slowing gastric emptying and reduced appetite.

3. Decreasing glucagon secretion.

Incretin hormones are rapidly inactivated by the DPP-4 enzyme. Sitagliptin inhibit DPP-4 enzyme and thereby prolong incretin activity ${ }^{27}$. Its mechanism of action schematically presented in the figure no. 3 .

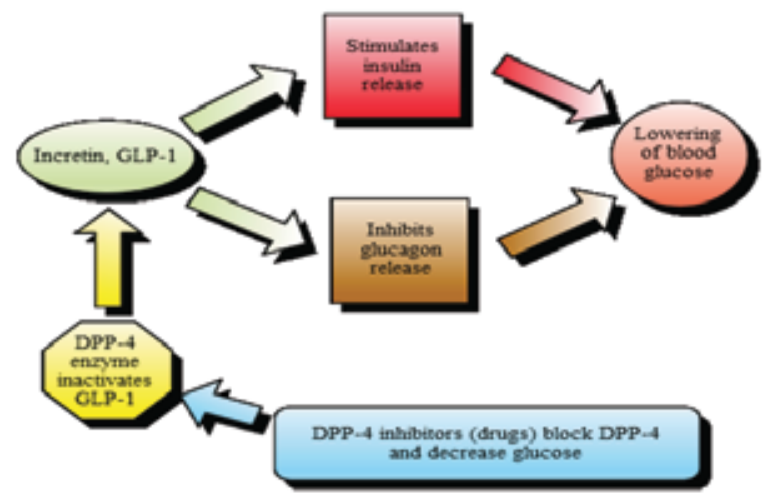

Figure-3: Mechanism of action of DPP-4 inhibitors ${ }^{27}$

Doses and duration of Sitagliptin for treatment of diabetes mellitus: Recommended dose is $100 \mathrm{mg}$ once daily, duration of action is 24 hours ${ }^{28}$.

Indication of Sitagliptin: Sitagliptin used as monotherapy and as add-on therapy to either of two other types of oral diabetes medications, metformin or thiazolidinediones in type 2 DM patient ${ }^{28}$.

Advantage: Weight loss, decreased pre and post prandial blood glucose, may associated with increase beta cell mass and survival ${ }^{7}$.

Disadvantage: Upper respiratory tract infection (Nasopharyngitis), may cause pancreatitis, may cause GIT upset28.Sitagliptin \& vildagliptin are two compounds of the DPP4 inhibitor class that have been approved in various countries ${ }^{28}$.

Pharmacology of Insulin glargine: Insulin glargineis a long-acting analog of human insulin that is produced following two alterations of human insulin. Two arginine residues are added to the $\mathrm{C}$ terminus of the $\mathrm{B}$ chain, and an asparagine molecule in position 21 on the $\mathrm{A}$ chain is replaced with glycine ${ }^{29}$.

Insulin glargine is a clear solution with a $\mathrm{pH}$ of 4.0 , which stabilizes the insulin hexamer. When injected into the neutral $\mathrm{pH}$ of the subcutaneous space, aggregations occurs, resulting in prolonged, but predictable, absorption from the injection site. Owing to insulin glargine's acidic $\mathrm{pH}$, it cannot be mixed with short-acting insulin preparations (i.e., regular insulin, aspart, or lispro) that are formulated at a neutral $\mathrm{pH}^{29}$.

In clinical studies glargine has a sustained peakless absorption profile, and provides a better once-daily 24-hour insulin coverage than NPH insulin. Evidence from clinical trials also suggests that glargine has a lower risk of hypoglycemia, particularly overnight compared to NPH insulin. Glargine may be administered at any time during the day with equivalent efficacy and does not accumulate after several injections. Glargine has been shown in clinical studies to normalize fasting (post absorptive) glucose levels following once-daily administration in patients with type 2 diabetes ${ }^{29}$. 
Sometimes, splitting the dose of glargine may be needed in very insulin-sensitive type 1 diabetes patients to achieve fasting (basal) glucose levels in the target range and avoid hypoglycemia. Unlike traditional insulin preparations that are absorbed more rapidly from the abdomen than from the arm or leg, the site of administration does not influence the time-action profile of glargine. Similarly, exercise does not influence glargine's unique absorption kinetics, even when the insulin is injected into a working limb ${ }^{29}$.

Glargine binds with a slightly greater affinity to IGF-1 receptors as compared with human insulin. However, this slightly increased binding is still approximately two log scales lower than that of IGF-1. Controversy currently exists whether glargine insulin is associated with an increased chance of malignancy or an acceleration of underlying malignancy, but most feel that the available evidence is circumstantial and not sufficiently convincing to change prescribing patterns ${ }^{29}$.

Discussion of safety and efficacy of using the agents using multi drug approach in uncontrolled type 2 diabetic patients: Aschner et al., (2012) conducted a comparative, parallel, randomized, open label trial of 6 months. In this 6 month study 732 patients with uncontrolled type 2 diabetes patients treated with metformin were enrolled. Then insulin glargine $(n=250)$ was given in one group subcutaneously at a dose of 0.2 unit $/ \mathrm{kg}$ body weight; while in another group, sitagliptin $(n=265)$ was given at a dose of $100 \mathrm{mg}$ once daily as add on therapy. At the end of 6 month period they concluded that insulin glargine was better in the achievement of optimum glycemic control in type 2 diabetes patients inadequately controlled by metformin ${ }^{30}$.

Arechavaleta et al., (2011) conducted a study to evaluate the efficacy and safety of adding sitagliptin $100 \mathrm{mg}$ daily or glimepiride (starting dose $1 \mathrm{mg}$ /day up to $6 \mathrm{mg} /$ day) to the treatment regimen of patients with type 2 diabetes mellitus with inadequate glycemic control on metformin monotherapy. They concluded that the addition of sitagliptin or glimepiride led to similar improvement of glycemic control after 30 weeks. Sitagliptin was generally well tolerated as compared to glimepiride. But treatment with sitagliptin was associated with a lower risk of hypoglycemia and weight loss while glimepiride was associated with weight gain ${ }^{31}$.

A 24 weeks, single blind study was conducted to assess the efficacy and safety of the sitagliptin (100 mg/day) added to ongoing metformin therapy who had inadequately glycemic control with metformin ( $\geq 1500 \mathrm{mg} /$ day) alone. They found sitagliptin with ongoing metformin therapy was efficacious and well tolerated in patients with type 2 diabetes ${ }^{32}$.

Nauck et al., (2006) conducted a study to compare the efficacy and safety of sitagliptin (100 mg qd) versus glipizide $5 \mathrm{mg} /$ day (up tritrated to a potential maximum up to $20 \mathrm{mg} /$ day) in patients with type $2 \mathrm{DM}$ and inadequately glycemic control on metformin monotherapy. After 52 weeks of study they concluded that, the addition of sitagliptin compared with glipizide provided similar HbA1c lowering efficacy. Sitagliptin was well tolerated with a lower risk of hypoglycemia related to glipizide and with weight loss compared with weight gain with glipizide ${ }^{33}$.

Sitagliptin has been studied as monotherapy and with other OHA. Aschner et al., (2006) studied sitagliptin as monotherapy on glycemic control in patient with type 2 DM. In this randomized, double blinded, placebo controlled study 741 patients (baseline HbA1c [A1C] $8.0 \%$ ) were randomized to sitagliptin $100 \mathrm{mg}$ or $200 \mathrm{mg}$ or placebo for 24 weeks. After the end of the study period they stated that once daily sitagliptin monotherapy improves glycemic control in the FBG, 2 hours Postprandial, HbA1c and was well tolerated in patients with type - 2 diabetes ${ }^{30}$.

Sudhakaran et al., (2011) conducted a 24 weeks study on type 2 DM patients whose glycemia was not controlled adequately (HbA1c >6.5) with OADs (either alone or combination). Then sitagliptin at a dose of $100 \mathrm{mg}$ once daily was added in addition to existing therapy in one group and insulin glargine as add on therapy in another group. At the end of the treatment period of 24 weeks they observed that sitagliptin significantly reduced $\mathrm{HbA} 1 \mathrm{c}$ and FBG in comparable to insulin glargine. Moreover, insulin glargine caused weight gain $(0.7 \mathrm{~kg})$ whereas sitagliptin caused small weight loss $[0.3 \mathrm{~kg}]^{34}$.

The efficacy and safety of sitagliptin as monotherapy were evaluated in Chinese, Indian and Korean patients with type 2 DM inadequately controlled by diet and exercise. In this randomized, placebo-controlled, double-blind, 18 week trial 530 patients received sitagliptin $100 \mathrm{mg}$ once daily or placebo. In this study, sitagliptin monotherapy for 18 weeks significantly improved glycemic control and was well tolerated in patients with type- 2 diabetes from China, India and Korea ${ }^{35}$.

\section{Conclusion}

Lifestyle modifications and metformin are the cornerstone of the initial management of T2DM, there is an increasing array of second and third-line pharmacological agents for this condition. At present there are different families of oral and injectable drugs, available for the treatment of T2DM. These include sulfonylureas, meglitinides, insulin, TZD and alpha-glucosidase inhibitors, and recently with the addition of RA-GLP1 receptor agonists, iDPP4 and iSGLT2. Moreover, insulin analogues that better simulate endogenous insulin secretion have been developed. Metformin remains the first choice of treatment for most patients. Other alternative or second-line treatment options should be individualized taking into consideration patient characteristics as degree of hyperglycaemia, presence of co-morbidities, and patient preference and ability to access treatments; and properties of the treatment such effectiveness and durability of lowering blood glucose, risk of hypoglycaemia, effectiveness in reducing diabetes complications, effect on body weight, side effects and contraindications. Although it does not appear that in the 
near future cure diabetes, novel safety and effective agents that will improve the quality of life of T2DM patients, are developing.

Conflict of Interests: None.

\section{Acknowledgement}

The authors thanks to Dr. K. M. Hafizur Rahman, Lecturer, Department of Pharmacology \& Therapeutics, Sylhet Women's Medical College, for his technical support in preparing this article.

\section{References}

1. American Diabetes Association. Executive Summary: Standards of Medical Care in Diabetes. Diabetes Care. 2014; 37: S5-S13.

https://doi.org/10.2337/dc14-S005

2. American Diabetes Association. Standards of Medical Care in Diabetes. Diabetes Care. 2014; 37: S14-S80.

https://doi.org/10.2337/dc14-S014

PMid:24357209

3. Centers for Disease Control and Prevention. National diabetes fact sheet: national estimates and general information on diabetes and prediabetes in the United States, 2011. Available at http:/www.cdc.gov/diabetes/ pubs/pdf/ndfs_2011.pdf. [Accessed on 5 May 2014].

4. American Diabetes Association. Diagnosis and Classification of Diabetes Mellitus. Diabetes Care. 2014; 37: S81-S90.

https://doi.org/10.2337/dc14-S081

PMid:24357215

5. Khan AKA, Mahtab H, Grant J, Stewart M, Ahmed T. Diabetes Mellitus. 3rd ed. Dhaka: BADAS; 2010.

6. Rahim MA, Rahman ML, Mostafa AW, Ahmed SF. The Prevalence Rate of Diabetes Mellitus (DM) in Rural Population of Bangladesh. Dinajpur Medical College Journal. 2011; 4: 41-48.

7. Barba C, Cavalli-Sforza T, Cutter J, Darntron-Hill I, Deurenberg P, Gill T, et al. Appropriate body-mass index for Asian populations and its implications for policy and intervention strategies. The Lancet. 2004; 363:157-163.

https://doi.org/10.1016/S0140-6736(03)15268-3

8. Wei GS, Coady SA, Goff DC Jr., Brancati FL, Levy D, Selvin E, et al. Blood pressure and the risk of developing diabetes in african americans and whites: ARIC, CARDIA, and the framingham heart study. Diabetes Care. 2011; 34: 873-879.

https://doi.org/10.2337/dc10-1786

PMid:21346180 PMCid:PMC3064044

9. Li Y, Qi Q, Workalemahu T, Hu FB, Qi L. Birth Weight, Genetic Susceptibility, and Adulthood Risk of Type 2 Diabetes. Diabetes Care. 2012; 35: 2479-2484.

https://doi.org/10.2337/dc12-0168

PMid:22923665 PMCid:PMC3507591
10. Wang J, Luben R, Khaw KT, Bingham S, Wareham NJ, Forouhi NG. Dietary energy density predicts the risk of incident type 2 diabetes: the European Prospective Investigation of Cancer (EPIC)-Norfolk Study. Diabetes Care. 2008; 31: 2120-2125.

https://doi.org/10.2337/dc08-1085

\section{PMid:18689693 PMCid:PMC2571060}

11. Khardori R. Type 2 Diabetes Mellitus. Emedicine [online]. Updated: Mar 24, 2014. Available from: http://emedicine.medscape.com/article/ 117853. [Accessed on 23 May 2014].

12. American Association of Clinical Endocrinologists. Statement on the Use of A1c for the Diagnosis of Diabetes. Available at https://www.aace.com/files/AACEposition A1cfeb2010.pdf. [Accessed on 14 May 2014].

13. World Health Organization. Definition and diagnosis of diabetes mellitus and intermediate hyperglycemia: report of a WHO/IDF consultation. World Health Organization, Geneva, 2006. Available at http://whqlibdoc.who.int/ publications/2006/9241594934eng.pdf. [Accessed on 12 January 2014].

14. Masharani U. Diabetes Demystified. United States: McGraw-Hill; 2008.

15. Cappola AR, Jameson JL. Diabetes Mellitus. In: Fauci AS, Braunwald E, Kasper DL, Hauser SL, Longo DL, Jameson JL, et al., editors. Harrison's Manual of Medicine.17th ed. New York: McGraw-Hill; 2009.

16. Pearson ER, McCrimmon RJ. Diabetes mellitus. In: Walker BR, Colledge NR, Ralston SH, Penman ID, editors. Davidson's Principles and Practice of Medicine. 22nd ed. Edinburgh: Elsevier, Churchill Livingstone; 2014.

17. Kennedy MSN. Pancreatic hormones and antidiabetic drugs. In: Katzung BG, Masters SB, Trevor AJ. Editors. Basic and Clinical Pharmacology. 12th edition. New York: The McGraw-Hill Companies; 2012.

18. Brown DC. Diabetes mellitus, insulin, oral antidiabetic agents, obesity. In: Benett PN, Brown MJ. Editors. Clinical Pharmacology. 10th edition. Edinburgh: Elsevier; 2008.

19. Cox ME, Rowell J, Corsino L, Green JB. Dipeptidyl peptidase- 4 inhibitors in the management of type 2 diabetes: safety, tolerability, and efficacy. Drug, Healthcare and Patient Safety. 2010; 2: 7-19.

https://doi.org/10.2147/DHPS.S6270

20. Klip A, Leiter LA. Cellular mechanism of action of metformin. Diabetes Care. 1990; 13: 696-704.

https://doi.org/10.2337/diacare.13.6.696

PMid:2162756

21. Badyal DK, Kaur J. Sitagliptin: a new class of oral drug for type 2 diabetes. The American Journal of Medical Sciences. 2008; 29: 97-98.

22. Drucker DJ, Sherman SI, Gorelick FS, Bergenstal RM, Sherwin RS, Buse JB. Incretin-based therapies for the treatment of type 2 diabetes: evaluation of the risks and benefits. Diabetes Care. 2010; 33: 428-433. 
https://doi.org/10.2337/dc09-1499

\section{PMid:20103558 PMCid:PMC2809297}

23. White JR. Dipeptidyl peptidase-IV inhibitors: pharmacological profile and clinical use. Clinical Diabetes. 2008; 26: 53-57.

https://doi.org/10.2337/diaclin.26.2.53

24. Scheen AJ. Pharmacokinetics of dipeptidylpeptidase-4 inhibitors. Diabetes, Obesity and Metabolism. 2010; 12: 648-658.

https://doi.org/10.1111/j.1463-1326.2010.01212.x

PMid:20590741

25. Gallwitz B. Review of sitagliptin phosphate: a novel treatment for type 2 diabetes. Vascular Health and Risk Management. 2007; 3: 203-210.

https://doi.org/10.2147/vhrm.2007.3.2.203

PMid:17580730 PMCid:PMC1994027

26. Powers AC, D'Alessio D. Endocrine Pancreas and Pharmacotherapy of Diabetes Mellitus and Hypoglycemia. In: Brunton LL, Chabner BA,Knollmann BC, editors. Goodman \& Gilman's The Pharmacological Basis of Therapeutics. 10th edition. The McGraw-Hill Companies: New York; 2011.

27. Aschner P, Chan J, Owens DR, Picard S, Wang E, Dain $\mathrm{M}-\mathrm{P}$, et al. Insulin glargine versus sitagliptin in insulin-naive patients with type 2 diabetes mellitus uncontrolled on metformin (EASIE): a multicentre, randomised open-label trial. The Lancet. 2012; 379: 2262-2269.

https://doi.org/10.1016/S0140-6736(12)60439-5

28. Arechavaleta R, Seck T, Chen Y, Krobot KJ, O'Neil EA, Duran L, et al. Efficacy and safety of treatment with sitagliptin or glimepiride in patients with type 2 diabetes inadequately controlled on metformin monotherapy: a randomized, double-blind, non-inferiority trial. Diabetes, Obesity and Metabolism. 2011; 13: 160-168.

https://doi.org/10.1111/j.1463-1326.2010.01334.x

PMid:21199268

29. Charbonnel B, Karasik A, Liu J, Wu M, Meininger G. Efficacy and safety of the dipeptidyl peptidase-4 inhibitor sitagliptin added to ongoing metformin therapy in patients with type 2 diabetes inadequately controlled with metformin alone. Diabetes Care. 2006; 29: 2638-2643.

https://doi.org/10.2337/dc06-0706

PMid:17130197
30. Nauck MA, Meininger G, Sheng D, Terranella L, Stein PP. Efficacy and safety of the dipeptidyl peptidase-4 inhibitor, sitagliptin, compared with the sulfonylurea, glipizide, in patients with type 2 diabetes inadequately controlled on metformin alone: a randomized, double-blind, non-inferiority trial. Diabetes, Obesity and Metabolism. 2007; 9: 194-205.

https://doi.org/10.1111/j.1463-1326.2006.00704.x

PMid:17300595

31. Sudhakaran C, Kishore U, Anjana RM, Unnikrishnan R, Viswanathan M. Effectiveness of sitagliptin in Asian Indian patients with type 2 diabetes-an Indian tertiary diabetes care center experience. Diabetes Technology and Therapeutics. 2011; 13: 27-32.

https://doi.org/10.1089/dia.2010.0120

PMid:21175268

32. Mohan V, Yang W, Son HY, Xu L, Nobel L, Langdon $\mathrm{RB}$, et al. Efficacy and safety of sitagliptin in the treatment of patients with type 2 diabetes in China, India, and Korea. Diabetes Research and Clinical Practice. 2009; 83:106-116. https://doi.org/10.1016/j.diabres.2008.10.009

PMid:19097665

33. Nauck MA, Meininger G, Sheng D, Terranella L, Stein PP. Efficacy and safety of the dipeptidyl peptidase-4 inhibitor, sitagliptin, compared with the sulfonylurea, glipizide, in patients with type 2 diabetes inadequately controlled on metformin alone: a randomized, double-blind, non-inferiority trial. Diabetes, Obesity and Metabolism. 2007; 9: 194-205.

https://doi.org/10.1111/j.1463-1326.2006.00704.x

PMid: 17300595

34. Sudhakaran C, Kishore U, Anjana RM, Unnikrishnan R, Viswanathan M. Effectiveness of sitagliptin in Asian Indian patients with type 2 diabetes-an Indian tertiary diabetes care center experience. Diabetes Technology and Therapeutics. 2011; 13: 27-32.

https://doi.org/10.1089/dia.2010.0120

PMid:21175268

35. Mohan V, Yang W, Son HY, Xu L, Nobel L, Langdon $\mathrm{RB}$, et al. Efficacy and safety of sitagliptin in the treatment of patients with type 2 diabetes in China, India, and Korea. Diabetes Research and Clinical Practice. 2009; 83: 106-116.

https://doi.org/10.1016/j.diabres.2008.10.009

PMid: 19097665 